\title{
Non-linear regression model as a replacement for seismic slowness log data in the construction of synthetic traces
}

Matheus R. S. Barbosa*, INCT-GP/UFBA, Alexsandro G. Cerqueira, INCT-GP/UFBA and Vinícius C. Santana, PPGEOFUFBA

Copyright 2021, SBGf - Sociedade Brasileira de Geofísica.

This paper was prepared for presentation during the $17^{\text {th }}$ International Congress of the Brazilian Geophysical Society held in Rio de Janeiro, Brazil, 8-11 November 2021.

Contents of this paper were reviewed by the Technical Committee of the $17^{\text {th }}$ International Congress of the Brazilian Geophysical Society and do not necessarily represent any position of the SBGf, its officers or members. Electronic reproduction or storage of any part of this paper for commercial purposes without the written consent of the Brazilian Geophysical Society is prohibited.

\section{Abstract \\ Summary}

The seismic well tie is an essential stage in seismic interpretation. It relates rock physical properties measured in a borehole with time travel data recorded during seismic reflection activity, providing the correct identification of seismic horizons (White \& Simm, 2003). It is possible to establish the time-depth model using the checkshot profile data to guide the positioning of the wavelets that composes the synthetic traces concerning the main seismic events.

We commonly define that the smaller is the distance between samples in the feature space, the more two samples are similar (Ertel, 2018). Applying the idea behind this statement over an $n$-dimensional feature space to build a regression model indicates that the K-Nearest Neighbor algorithm can predict the value of a sample. Thereby, this algorithm was implemented and optimized to estimate the sonic log data in order to carry out the seismic well tie and compare the two synthetic seismic traces generated.

The dataset adopted in the experiments holds numerical and categorical information of twenty-one wells containing Gamma-Ray (GR), Deep Induced Resistivity (RILD), Short Induced Resistivity (RILS) logs, and Geological Formation. Twenty of them were applied to train the regression model, while the last one was separated to be the blind test. The density, sonic, and predicted sonic logs made it possible to generate synthetic traces from the blind test. We evaluate them through the visual analysis of their peaks and amplitudes, as much as the seismic well tie of both synthetic traces with the surrounding seismic data, aiming to verify if the predicted slowness log can replace measured data in well tie procedure.

\section{Results}

During the sonic data prediction stage, we performed the holdout cross-validation method in which $75 \%$ of the dataset was used to train the regression model, whilst the other $25 \%$ was used to evaluate the built model's generalization capacity. Furthermore, the parameter optimization by minimizing the mean absolute error (MAE) in training and test data points out that the number of neighbors equals 15 produces the most suitable regression model. The train and test dataset MAEs were respectively $6.51 \mu \mathrm{s} / \mathrm{ft}$ and $7.10 \mu \mathrm{s} / \mathrm{ft}$. In the blind test, the MAE was
$12.26 \mu \mathrm{s} / \mathrm{ft}$. In the second stage, the synthetic traces were generated. Afterward, the synthetic traces are shown in Figure 1, together with the sonic, acoustic impedance log and the reflectivity series.
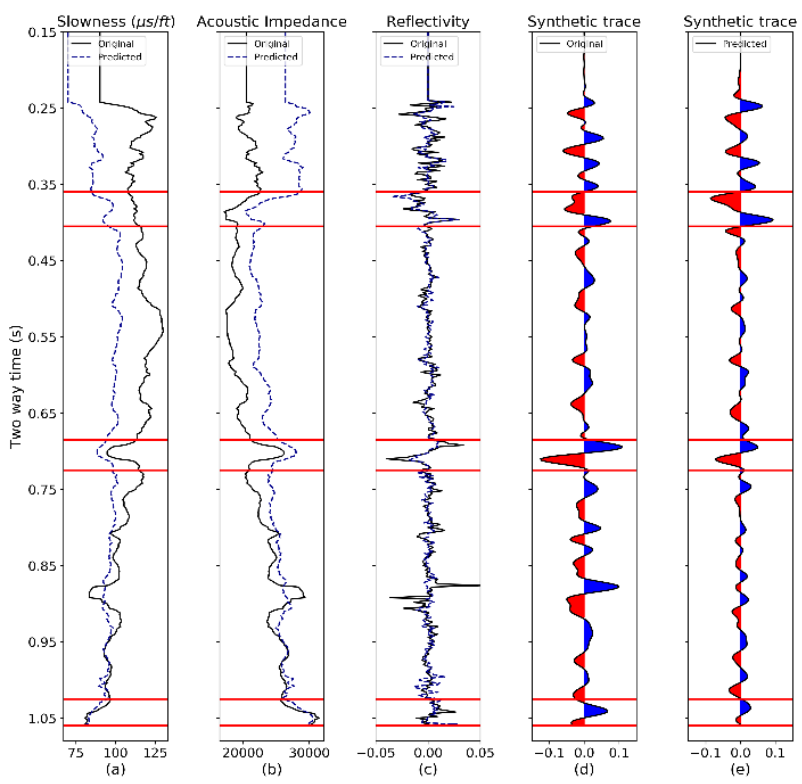

Figure 1 - Synthetic traces generated from the sonic log data and the predicted slowness log data. The three time intervals highlighted by the red lines indicates the main contrasts of acoustic impedance that characterize the leading seismic events.

\section{Conclusions}

The comparison between the two synthetic traces showed promising results with regards to the visual analysis of the peaks and amplitudes of the main seismic events. Both traces look similar, especially in relation to the alignment of the wavelet peaks. The results also presented a good Pearson correlation between both synthetic traces: 0.7 .

\section{References}

White, R; Simm, R. Tutorial: Good practice in well ties. First Break, 2003.

Simm, R, and M Bacon. Seismic amplitude: an interpreter's handbook. Cambridge New York: Cambridge University Press, 2014. Print.

Ertel, W. Introduction to artificial intelligence. Springer, 2018. 